\title{
Da Biopolítica ao Biograma \\ ou como Leni Riefenst Ahl Move-se Através do Fascismo
}

\author{
Erin Manning ${ }^{1}$ \\ Tradução e adaptação Bianca Scliar²
}

\begin{abstract}
Resumo:
Publicado originalmente no livro Relationscapes, movement, art, philosophy (M.I.T University Press, 2009), o artigo é uma versão reduzida do capítulo em que a autora Erin Manning discute a polêmica junção entre produção estética e ideologias políticas. Na celebração dos vinte anos do tribunal de Nüremberg e com a recente biografia fílmica de Hannah Arendt, o tema volta à tona, quando observamos movimentos ressurgentes de controle das manifestações estéticas. Manning discute o brilhantismo de Riefenstahl a partir de uma cuidadosa análise de Olympia, considerando os movimentos de câmara como estratégia de invenção do corpo em si, tecendo uma especulação sobre as ideologias contidas nos gestos retratados e inventados em cena. Os argumentos desviam-se das acusações políticas recorrentes para alcançar a obra de Riefenstahl como representativa na discussão sobre o limite das aparências e o transcendentalismo físico no cinema. Em um movimento teórico único, a produção da cineasta é comparada ao de seus contemporâneos do movimento futurista.
\end{abstract}

\begin{abstract}
:
Originally publishedinthebookRelationscapes , movement, art, philosophy (MIT University Press, 2009), this article is an abridged version of the chapter in which the author discusses the controversial junctions between aesthetic, art making and political ideologies. In celebration of the twentyth aniversary of the Nuremberg Tribunal and the recent film biography of Hannah Arendt, the junctions resurfaces as a key topic for aesthetics today. Manning discusses the brilliance of Riefenstahl from a careful analysis of Olympia, considering the camera movements become an invention of the body itself, speculating around the ideologies contained in the portrayed gestures by still objects, invented in the film. The arguments deviate from the recurrent charges around the work of Riefenstah, and allow for a meaningfull discussion about the limits of transcendentalism and physical appearances in movies. As a theorical move, the filmmaker is compared to her contemporaries from the Futurist movement
\end{abstract}

Palavras- Chave:Leni-Riefenstahl, Filosofia do Movimento, Futurismo e o Corpo.
Keywords: Leni-Riefenstahl, Movement Philosophy, Futurism and the Body.

\footnotetext{
$1 \quad$ Artista e professora titular de arte relacional, filosofia e cinema na Concordia University (Canadá)

2 Artista multidisciplinar e Professora Adjunto no Curso de Graduação em Dança da UFRGS.
} 
"O gesto que seria reproduzido na tela não deve mais ser um momento fixo no dinamismo universal. Deve simplesmente ser a própria sensação da dinâmica em si". (Umberto Boccioni em "Pintura futurista: um manifesto técnico, 1910")
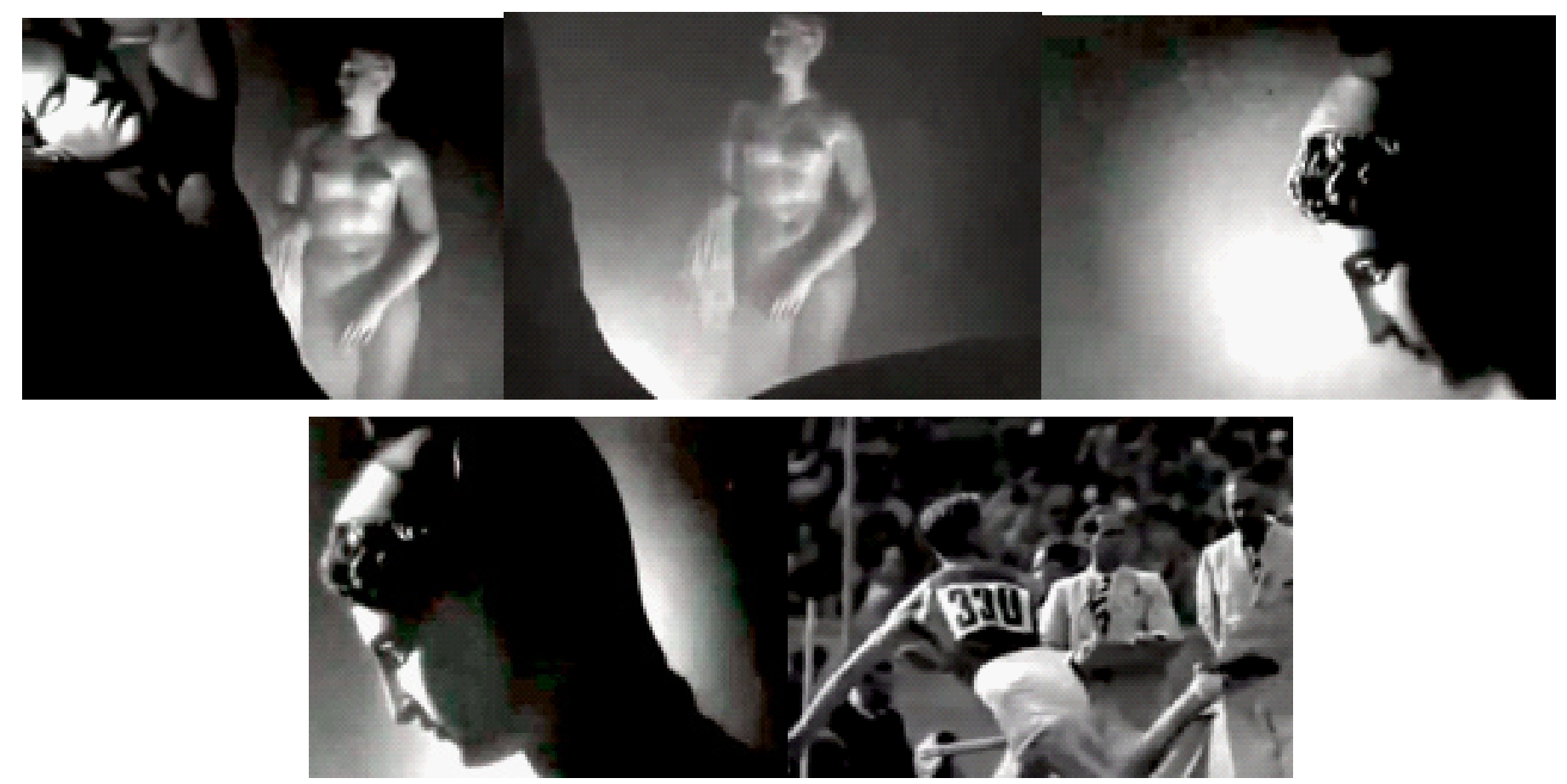

Imagem 1 a 5: Captura de tela de Olympia parte 1, o Festival do Povo (Riefenstahl, 1938)

Olympia parte 1, o Festival do Povo (Riefenstahl, 1938) inicia com os créditos cravados em pedra. Enquanto as letras abrem caminho para a primeira imagem, o congelamento ganha vida. Corpos em pedra tornam-se corpos em movimento, emergindo em uma lenta dança enquanto a câmera circula as ruínas do sítio Olímpico arcaico. A dança lenta da câmera é acompanhada pela sensação da pedra ganhando vida.

Percebemos um movimento duplo: a música prepara a atmosfera que transforma as ruínas em formas mutantes, dando caminho a um céu temperamental. O céu é protagonista: acorda lentamente, o sol lânguido atravessa a opacidade da imagem. Simultaneamente com a transformação gradual da alvorada em dia, a câmera move-se criando uma sensação de metamorfose. Quando finalmente alcançamos a estrutura do Parthenon, um sentimento de transformação prolongada cravou-se pelas permutações da paisagem. Fomos guiados pela estranha passagem da transfiguração. Na abertura de Olympia, Riefensthal não mostra apenas um campo em ruínas. Ela o leva à vida.

A câmera, desde a primeira sequência, quando atravessa a pedra, se apresenta de forma dinâmica. Isso é um artifício reminiscente do Triunfo da Vontade (1935), onde Riefenstahl filma a aproximação de Hitler, Himmler e Hess. Enquanto assistimos às três figuras moverem-se até nós, um pan é iniciado atrás de grandes colunas, que repetidamente bloqueiam a visão do espectador. O paradoxo desta técnica é que a obstrução momentânea e repetida da presença física tem o efeito curioso de intensificar 
o evento de sua chegada. Sentimos a força virtual de sua importância a partir do momento em que seus corpos de fato somem. Na aproximação da câmera do Parthenon vemos o mesmo efeito. Sentimos que o Parthenon nos ganha antes mesmo de vê-lo. O que vemos está saturado pelas sensações do que não podemos ver: a imagem reajusta-se pela intensidade do movimento da câmera. Há então a aparição áurea e impositiva da lembrança de uma era perdida: uma longa sequência do Parthenon completamente centralizado. O jogo se estabelece aqui entre a fluidez e a materialidade. A materialidade se apresenta pela densidade das ruínas, a fluidez na graciosidade que toma forma na passagem intensa da aparição à desaparição.

Então uma face, feita de pedra e, entretanto, quase viva, uma escultura quasi-carne ganha a cena. O objeto é tomado em dissolução enquanto a música se dissipa. Trompetes soam e uma outra face entra em quadro, em um close-up sobre um fundo escuro, capturado entre o dia e a noite. Vindo de baixo, a próxima figura em pedra reaparece, movendo-se ainda, tomando forma a partir da desaparição da face anterior. Um movimento imanente transluz na opacidade da superfície da pedra: uma transcendência física.

Da pedra à carne, da noite ao dia, da aparição à desaparição surge finalmente a primeira criatura viva: um corpo de pedra de um lançador de disco que começa a se mover. Assistimos à magnífica transformação da incipiência ao deslocamento. O corpo foi criado e já é em si mais do que apenas um. Em Olympia o protagonista não é o corpo como tal, mas a qualidade que o permite vir à vida em relação a um ambiente sempre emergente.

Pense sobre o lançador de disco: lentamente a câmera circula e o movimento do corpo ganha forma em espiral. O corpo ainda não está se movendo-se, mas a terra se mexe. Tão logo a espiral se abre, o corpo começa a se agitar e sua pré-aceleração arrebenta a carne da pedra. O corpo se move apenas quando toda a imagem está em movimento: o que experimentamos é puro movimento. José Gil o chama de movimento total; um movimento que qualitativamente altera a capacidade transformativa do próprio corpo, que não se encerra na forma pressuposta no que entendíamos até então como os limites daquele corpo.

Riefensthal torna aparente, a partir de sequências de movimentos, a noção do quanto o movimento é infinitamente maior do que o deslocamento que o compõe. Sugere assim que o corpo não é um ente formal que realiza um percurso, mas ele emerge na incipiência do movimento em movimento. Temos contato, nesta primeira sequência do filme, com uma experiência de corpo, e não com uma forma corporal. O corpo para Riefenstahl é aquilo que aparece entre a imagem e o movimento.

Na sequência seguinte vê-se a ondulação da grama e o braço numa dança transcendental entre a imaterialidade aparente e o corpo que reconheço como a formalização cinemática do transcendentalismo material. O corpo não toma forma, permanecendo transcendental em sua imanência. O que dança não é o corpo, mas o intervalo entre encontros com a grama. Este intervalo chamarei de biograma e é o que dá forma ao trabalho de Riefenstahl.

Olympia jamais apresenta um corpo estável, mas estabelece um corpo que provoca relações entre amarrações de aparição e desaparição, formadas pela intensidade das imagens, em sua capacidade de dar forma ao movimento de transformação. Vê-se o corpo invariavelmente em uma materialidade 
esplêndida, mas mantido na iminência do desaparecimento. Esse corpo-em-formação é tão vivo como a luz que dança ao redor dos braços retratados por Riefensthal sobre a grama e tão virtual quanto o movimento fluido da pedra, incorporando uma estética terrivelmente fascista mas inventiva do ponto de vista da biopolítica. O fascismo não é um ready-made, e nem localiza-se em um corpo que tem forma pré-estabelecida. Em Olympia encontramos um fascismo muito mais evasivo: o fascismo do entremeio, onde a biopolítica suscita biogramas.

No caso de Riefenstahl, argumento que o biograma aparece na técnica de recombinação significativa do corpo que não cessa na forma. O biograma é a conjugação de ritmos de aparição e desaparição, da velocidade à lentidão, expresso nas dinâmicas de movimento. Nos biogramas experimentamos a esfoliação ao invés da bola, o voo ao invés do dardo, emaranhados e não membros. Sentimos a qualidade da elasticidade anteceder o contorno. No exemplo da sequência do dardo, na repetição do ato de atirar, o atiramento torna-se o corpo: o movimento declama-se substantivo na ação.

\section{Transcendentalismo Físico}

Os ecos do futurismo povoam o inicio do cinema e também o trabalho de Riefenstahl. Tanto Boccioni (fundador e signatário do manifesto futurista) quanto Riefenstahl exploram como a integridade de um movimento (sua indivisibilidade) desafia a ideia de um espaço pré-existente. Este é um problema bergsoniano: como pensar o espaço como algo que não é pré- existente sem espacializar o vazio potencial da passagem do tempo? Para Bergson o problema é que, se o espaço preexiste ao movimento - ou seja, se o espaço é um contêiner para o movimento - então o movimento deve poder ser percebido como algo que inicia e cessa por completo.

Para Bergson o movimento diferencia-se do espaço ocupado. O espaço percorrido é divisível, enquanto o movimento é sempre indivisível. Nem Bergson nem Boccioni extrapolariam suas teses sobre movimento na cinemática, mas aparentemente Riefenstahl toma o desafio para si, criando um vocabulário de durações de movimento. O filme de Riefenstahl deixa claro que o movimento cinemático não opera apenas entre o corte e o enquadramento, mas faz-se sentir a partir de suas sequências.

Tal como na afirmação de Boccioni de que "nossos corpos penetram os sofás onde sentamos, e o sofá penetra nossos corpos", Riefenstahl insiste em pensar a imagem de modo relacional. Institui um artifício estilístico na recusa em considerar o movimento a partir de uma imagem pré-existente.

Para Boccioni há uma conexão implícita entre ritmo e força. As linhas de força são o que trazem vida à materialidade. Em Riefenstahl elas movem-se intensamente, dobrando-se em topologias e transformações através de cada sequência, expressando as potencialidades de movimento da matéria. A matéria torna-se força antes de tomar forma.

O filme de Riefenstahl, tal qual em Boccioni, reafirma a definição de formas pelo movimento e privilegia a expressividade em detrimento de um conteúdo. O estabelecimento de uma forma dinâmica sugere que Riefenstahl compõe com o fascismo mas não atua no estabelecimento de um corpo fascista 
(disciplinado). O que compõe é a expressão de um corpo em transformação simbiótica, associado ao fascismo, mas que excede sua disciplinaridade. Inicia com o belo, jovem, forte, mas não se ocupa com um corpo específico, particular.

É importante questionarmos como o trabalho de Riefenstahl toma forma hoje, como sua reiteração após mais de meio século é sustentada e como ele define e encontra-se com outras formas com as quais continua a ressoar. As imagens de Riefenstahl jamais serão desconectadas do fascismo. Entretanto, podemos associar a força da corporalidade que propõe a partir da transcendência que seu trabalho prevê.

Riefenstahl está certa ao afirmar que não encena encontros políticos em sua obra. Sua política não é pré-estabelecida. É uma política de afetos. A partir de seus biogramas mutantes abre-se para afetos que ressoam através de corpos. Essa política, característica do fascismo, encontra na indefinição das formas a sua mais poderosa capacidade de mobilização, muito além daquilo o que Hitler chamou de estética fascista.

Diferentemente desta, a estética-afetiva de Riefenstahl não se ocupa consigo própria, nem em disciplinar um corpo esquivo. Ela cria em afetos um movimento incipiente. A política do afeto não é uma política moral. Uma ênfase no movimento não promete uma política emancipatória. É mais perigosa, posto que sugere uma recomposição que define o que pode fazer o corpo, deixando para trás o sujeito relacional moderno kantiano.

Ao produzir sequências de biogramas que operam contra tendências singulares, povoando a tela com movimentos que não se individualizam, a cineasta chama para recomposições qualitativas de gestos, possibilita a preparação de desejos expressados imaterialmente. 